ScIDoC

\section{Preference Of Root Canal Sealers Used By Dental Students In Treatment Of Immature Non-Vital Permanent Tooth}

Research Article

\author{
Sowmya G.S ${ }^{1}$, Mebin George Mathew ${ }^{2 *}$, Sankari Malaiappan ${ }^{3}$
}

${ }^{1}$ Saveetha Dental College And Hospitals, Saveetha Institute Of Medical and Technical Sciences, Saveetha University, Chennai,600050, India.

${ }^{2}$ Senior Lecturer, Department of Pediatric and Preventive Dentistry, Saveetha Dental College and Hospitals, Saveetha Institute Of Medical And Technical Sciences, Saveetha University, Chennai, India.

${ }^{3}$ Professor, Department of Periodontics, Saveetha Dental College and Hospitals, Saveetha Institute Of Medical And Technical Sciences, Saveetha University, Chennai, India.

\title{
Abstract
}

To evaluate the preference of root canal sealers used by dental students for the treatment of immature non vital permanent teeth. Materials and methods: Retrospective data of pediatric dental patients with immature non vital permanent teeth was obtained using digital information archive system. A total of 19 patients who fulfilled the criteria were included in the study. Data was analysed using SPSS software version 20.0

Results: $84 \%$ of the patients were male. The most preferred sealer was resin based sealer $(41 \%)$ followed by zinc oxide based sealers $(35 \%)$. The least preferred was calcium hydroxide based sealers $(24 \%)$

Conclusion: The most preferred sealer by dental students was resin based sealer followed by zinc oxide based sealers.

Keywords: Apexification; Immature Teeth; Non Vital; Open Apex; Sealer.

\section{Introduction}

Dental trauma is a relatively common occurrence during childhood. Depending on its magnitude, it may produce concussion, luxation, fracture, or avulsion of the teeth, leading, in more severe cases, to necrosis of the pulp tissue $[14,9]$. When pulp regeneration or repair is not possible, the endodontic treatment of immature permanent necrotic teeth is more time-consuming and technically more difficult than conventional procedures because these teeth present widened root canals and open apices [15]. The tooth roots may also suffer external infection-related (inflammatory) root resorption or alterations of their formation during treatment [8].

In cases of infected pulps, it is necessary to use a specific dressing material to neutralize the bacteria and their products and to stimulate the apexification process by forming a mineralized apical barrier so that the subsequent condensation of gutta-percha can be properly achieved [10]. Traditionally, apexification has been performed for treatment of immature non vital permanent [22].

Accomplishment of ideal root canal treatment is attributed to various essential factors such as proper instrumentation, biomechanical preparation, obturation, and ultimately depending upon the case post-endodontic restoration [15]. The pertinent aim of this treatment is to do away with the microbial entity and any future predilection of re-infection. In order to achieve this, proper seal is required to denigrate any chance of proliferation of bacteria and future occurrence of any pathology. Sealer along with solid obturating material acts synergistically to create hermetic seal [8].

Treatment of immature permanent teeth is a challenge for the clinician due to thin walls which are prone to fracture and divergent open apices along with cooperative ability of the child. Hence the choice of sealer is an important decision. Thus, this study was undertaken with the aim to to evaluate the preference of root canal sealers used by dental students for the treatment of immature non vital permanent teeth.

*Corresponding Author:

Dr. Mebin George Mathew,

Senior Lecturer, Department of Pediatric and Preventive Dentistry, Saveetha Dental College and Hospitals, Saveetha Institute Of Medical And Technical Sciences, Saveetha

University, Chennai, India.

Tel: $+91-8951748659$

E-mail: mebingeorgem.sdc@saveetha.com

Received: July 23, 2020

Accepted: August 17, 2020

Published: August 29, 2020

Citation: Sowmya G.S, Mebin George Mathew, Sankari Malaiappan. Preference Of Root Canal Sealers Used By Dental Students In Treatment Of Immature Non-Vital Permanent Tooth. Int J Dentistry Oral Sci. 2020;S8:02:0020:100-102. doi: http://dx.doi.org/10.19070/2377-8075-SI02-080020

Copyright: Mebin George Mathew 2020 . This is an open-access article distributed under the terms of the Creative Commons Attribution License, which permits unrestricted use, distribution and reproduction in any medium, provided the original author and source are credited. 


\section{Materials and Methods}

The present study was undertaken in the Department of Pediatric and Preventive Dentistry, Saveetha Dental College after obtaining approval from the Scientific Review Board. Retrospective data was obtained by going through the case records of pediatric dental patients who visited the Department of pediatric and Preventive Dentistry at Saveetha Dental College from June 2019 to March 2020. Patients younger than 18 years of age with immature permanent non vital teeth who had completed treatment during the study period were included in the study. Patients older than 18 years and children with systemic diseases were excluded. A final sample size of 19 patients was obtained. Data was verified by one external reviewer and was statistically analysed using SPSS version 20.0 .

\section{Results and Discussion}

A total of 19 patients had received treatment for immature permanent non vital teeth during the study period. The ages of the patients varied from 8 to 16 years out of which of $3(16 \%)$ were girls and $16(84 \%)$ were boys (Graph 1). 14 year old patients were most affected $(19 \%)$ whereas 8 year olds were least affected (Graph 2). $41 \%$ of the dental students preferred resin based sealers whereas $35 \%$ preferred zinc oxide based sealers and $24 \%$ chose calcium hydroxide sealers. (Graph 3).

Apexification is a method of treatment for immature permanent teeth in which root growth and development ceased due to pulp necrosis. Its purpose is to induce root end closure with no canal wall thickening or continuous root lengthening [21]. It can be achieved in two ways: (a) as a long-term procedure using calcium hydroxide dressing to allow the formation of a biologic hard tissue barrier, or (b) as a short-term (more recent) procedure, creating an artificial apical plug of MTA or other bioceramic material. Apexification is most often performed in incisors that lost vitality because of traumatic injury, after carious exposures, and in teeth with anatomic variations such as dens invaginatus with an immature root $[20,5]$.

The apex in immature teeth may present two morphologic varia-

Graph 1. Bar graph showing the association between age and tooth number. $\mathrm{X}$-axis represents the age and $\mathrm{Y}$-axis represents the tooth number. Chi square test done and association was found to be statistically not significant. Pearson's Chi square value $: 13.172$, $p$ value:0.902( statistically not significant).

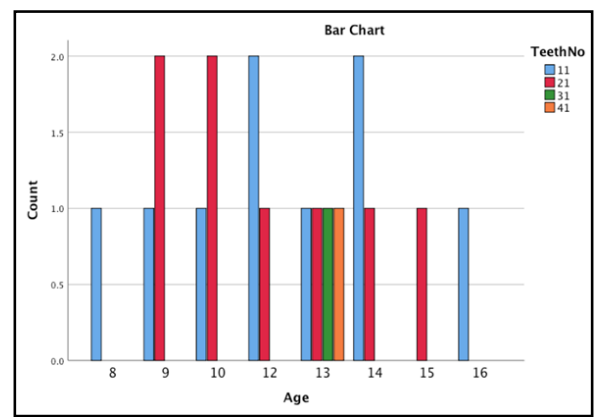

Graph 2. Bar graph showing the association between age and choice of sealer.X-axis represents the age and Y-axis represents the sealer. Chi square test done and association was found to be statistically not significant. Pearson's chi square value :2.215, p value: 0.764 (statistically not significant).

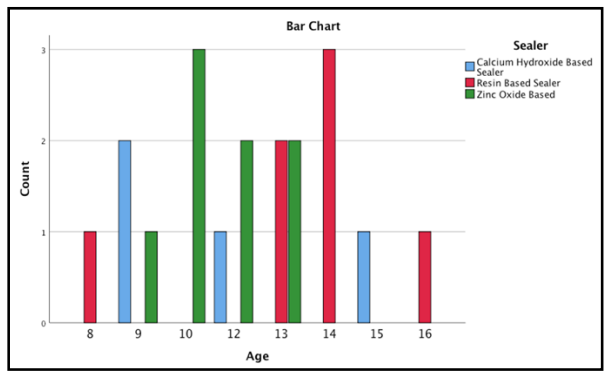

Graph 3. Bar graph showing the association between gender and choice of sealer. $\mathrm{X}$-axis represents the gender and $\mathrm{Y}$-axis represents the sealer. Chi square test done and association was found to be statistically not significant. Pearson's chi square value : 5.033 , $p$ value: 0.868 (statistically not significant).

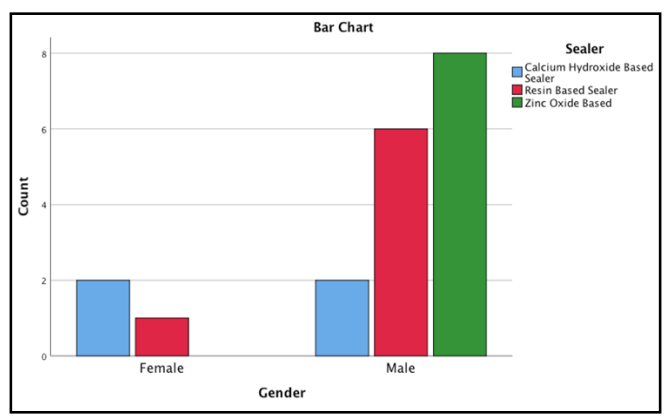


tions: divergent with flaring apical foramen (blunderbuss apex) or parallel to convergent [19]. This morphology is difficult to determine because of the two-dimensional image obtained by dental radiographs. In both forms, conventional endodontic treatment cannot be performed, because it is difficult if not impossible to achieve an apical seal that will prevent extrusion of the filling material [12]. When apexification is carried out successfully in teeth with radiographic signs of rarefying osteitis, healing of the bone will be observed gradually. The tooth should continue to erupt, and the alveolar bone should continue to grow in conjunction with the adjacent teeth. Follow-up should be performed to ensure the absence of adverse posttreatment clinical and radiographic signs [11].

The quality of the seal obtained with gutta-percha (GP) and conventional zinc oxide eugenol (ZOE) sealers is quite far from being perfect [23] Also, despite its multiple strong points, GP and conventional sealer combination still has its own shortcomings, like its inability to strengthen root, as it does not adhere to dentin, inability to control microleakage, and the solubility of sealer makes prognosis dilemmatic and un-assuring Although few materials are capable enough to swap GP on multiple parameters, research continues to find alternatives that may seal better and mechanically reinforce compromised roots by forming monoblock, which has been suggested to reduce bacterial ingress pathways and strengthen the root to some extent. [16],(Bouillaguet et al., 2008) Hence, several new resin cement sealants have been developed to be used instead of ZOE, thereby improving the root canal seal and imparting it more strength as compared to the conventional materials $[3,4]$. These include silicon-based sealers which are well tolerated by tissues, have low water sorption, and have a potential of forming monoblock, thus reinforcing root canal [17], epoxy resin-based sealers with the possibility of adhesion to dentin and with lower rates of water solubility [24], and mineral trioxide aggregate (MTA)-based sealers which have the predilection toward mineralization along with all the viable properties of orthodox sealers [13]. Nevertheless, resin-based and silicon-based materials are also soluble, which may endanger a proper seal, although the solubility of resin-based materials is usually lesser than that of ZOE (which is reported as between 1\% and 7\%) [1, 6] and does not exceed a maximum weight loss of $3 \%$ within $24 \mathrm{~h}$ of distilled water storage (in accordance with the standards for Root Canal treatment sealer ( $\mathrm{R} \mathrm{Cl} \mathrm{T)} \mathrm{[18].} \mathrm{Accordingly,} \mathrm{availability} \mathrm{of} \mathrm{so} \mathrm{many}$ sealers makes it impossible for the clinician to decide what to avail and when. So, the purpose of the article is to create awareness about the different types of sealers and their pros and cons [2]. Every manufacturer claims its product to be the ideal one, but only the clinical results can give the affirmation or negation of that particular sealer.('Fluoride, Fluoridated Toothpaste Efficacy And Its Safety In Children - Review', 2018) Till date, none of the sealers has proved to be the ideal except a few which can come closer to being one.

The most preferred sealer in the present study was resin based sealers. This could be due to the fact that epoxy resin-based sealers are widely used for root canal filling due to their resorption resistance and dimensional stability [24]. Most recently introduced bioceramic-based materials have attractive physical, chemical, mechanical, and biological properties [7].

\section{Conclusion}

Students preferred the use of resin based sealers over zinc oxide based and calcium hydroxide based sealers. However, only long term follow up of these cases will let us now the clinical success of these studies.

\section{References}

[1]. Andreasen JO, Munksgaard EC, Bakland LK. Comparison of fracture resistance in root canals of immature sheep teeth after filling with calcium hydroxide or MTA. Dental traumatology. 2006 Jun;22(3):154-6.

[2]. Bae WJ, Chang SW, Lee SI, Kum KY, Bae KS, Kim EC. Human periodontal ligament cell response to a newly developed calcium phosphate-based root canal sealer. J Endod. 2010 Oct;36(10):1658-63. Pubmed PMID: 20850672.

[3]. Bouillaguet S, Shaw L, Barthelemy J, Krejci I, Wataha JC. Long-term sealing ability of Pulp Canal Sealer, AH-Plus, GuttaFlow and Epiphany. Int Endod J. 2008 Mar;41(3):219-26. Pubmed PMID: 18005042.

[4]. Camps J, Pommel L, Bukiet F, About I. Influence of the powder/liquid ratio on the properties of zinc oxide-eugenol-based root canal sealers. Dent Mater. 2004 Dec;20(10):915-23. Pubmed PMID: 15501319.

[5]. Christabel SL, Gurunathan D. Prevalence of type of frenal attachment and morphology of frenum in children, Chennai, Tamil Nadu. World J Dent. 2015 Oct;6(4):203-7.

[6]. Ramakrishnan M, Bhurki M. Fluoride, Fluoridated Toothpaste Efficacy And Its Safety In Children-Review. International Journal of Pharmaceutical Research. 2018 Oct 1;10(04):109-14.

[7]. Gogos C, Economides N, Stavrianos C, Kolokouris I, Kokorikos I. Adhesion of a new methacrylate resin-based sealer to human dentin. J Endod. 2004 Apr;30(4):238-40. Pubmed PMID: 15085055.

[8]. Govindaraju L, Gurunathan D. Effectiveness of Chewable Tooth Brush in Children-A Prospective Clinical Study. J Clin Diagn Res. 2017 Mar;11(3):ZC31-ZC34. Pubmed PMID: 28511505.

[9]. Govindaraju L, Jeevanandan G, Subramanian E. Clinical Evaluation of Quality of Obturation and Instrumentation Time using Two Modified Rotary File Systems with Manual Instrumentation in Primary Teeth. J Clin Diagn Res. 2017 Sep;11(9):ZC55-ZC58. Pubmed PMID: 29207834.

[10]. Govindaraju L, Jeevanandan G, Subramanian EMG. Comparison of quality of obturation and instrumentation time using hand files and two rotary file systems in primary molars: A single-blinded randomized controlled trial. Eur J Dent. 2017 Jul-Sep;11(3):376-379. Pubmed PMID: 28932150.

[11]. Govindaraju L, Jeevanandan G, Subramanian EM. Knowledge and practice of rotary instrumentation in primary teeth among indian dentists: A questionnaire survey. Journal of International Oral Health. 2017 Mar 1;9(2):45.

[12]. Gurunathan D, Shanmugaavel AK. Dental neglect among children in Chennai. J Indian Soc Pedod Prev Dent. 2016 Oct-Dec;34(4):364-9. Pubmed PMID: 27681401.

[13]. Hatibović-Kofman S, Raimundo L, Zheng L, Chong L, Friedman M, Andreasen JO. Fracture resistance and histological findings of immature teeth treated with mineral trioxide aggregate. Dent Traumatol. 2008 Jun;24(3):272-6. Pubmed PMID: 18410392.

[14]. Jeevanandan G. Kedo-S Paediatric Rotary Files for Root Canal Preparation in Primary Teeth - Case Report. J Clin Diagn Res. 2017 Mar;11(3):ZR03ZR05. Pubmed PMID: 28511532.

[15]. Jeevanandan G, Govindaraju L. Clinical comparison of Kedo-S paediatric rotary files vs manual instrumentation for root canal preparation in primary molars: a double blinded randomised clinical trial. Eur Arch Paediatr Dent. 2018 Aug;19(4):273-278. Pubmed PMID: 30003514.

[16]. Lakshmanan L, Mani G, Jeevanandan G, Ravindran V, Ganapathi SE. Assessing the quality of root canal filling and instrumentation time using kedo-s files, reciprocating files and k-files. Brazilian Dental Science. 2020 Jan 31;23(1):7-p.

[17]. Lertchirakarn V, Timyam A, Messer HH. Effects of root canal sealers on vertical root fracture resistance of endodontically treated teeth. J Endod. 2002 Mar;28(3):217-9. Pubmed PMID: 12017185.

[18]. Milani AS, Rahimi S, Borna Z, Jafarabadi MA, Bahari M, Deljavan AS. Fracture resistance of immature teeth filled with mineral trioxide aggregate or calcium-enriched mixture cement: An ex vivo study. Dent Res J (Isfahan). 2012 May;9(3):299-304. Pubmed PMID: 23087735.

[19]. Packiri S, Gurunathan D, Selvarasu K. Management of Paediatric Oral Ranula: A Systematic Review. J Clin Diagn Res. 2017 Sep;11(9):ZE06-ZE09. Pubmed PMID: 29207849. 
[20]. Panchal V, Jeevanandan G, Subramanian E. Comparison of instrumentation time and obturation quality between hand $\mathrm{K}$-file, $\mathrm{H}$-files, and rotary Kedo-S in root canal treatment of primary teeth: A randomized controlled trial. J Indian Soc Pedod Prev Dent. 2019 Jan-Mar;37(1):75-79. Pubmed PMID: 30804311.

[21]. Ravikumar D, Jeevanandan G, Subramanian EMG. Evaluation of knowledge among general dentists in treatment of traumatic injuries in primary teeth: A cross-sectional questionnaire study. Eur J Dent. 2017 AprJun;11(2):232-237. Pubmed PMID: 28729799.

[22]. Somasundaram S, Ravi K, Rajapandian K, Gurunathan D. Fluoride Content of Bottled Drinking Water in Chennai, Tamilnadu. J Clin Diagn Res.
2015 Oct;9(10):ZC32-4. Pubmed PMID: 26557612.

[23]. Subramanyam D, Gurunathan D, Gaayathri R, Vishnu Priya V. Comparative evaluation of salivary malondialdehyde levels as a marker of lipid peroxidation in early childhood caries. Eur J Dent. 2018 Jan-Mar;12(1):67-70. Pubmed PMID: 29657527.

[24]. Upadhyay V, Upadhyay M, Panday RK, Chturvedi TP, Bajpai U. A SEM evaluation of dentinal adaptation of root canal obturation with GuttaFlow and conventional obturating material. Indian J Dent Res. 2011 NovDec;22(6):881. Pubmed PMID: 22484899. 